\title{
SURVEI SARANA DAN PRASARANA PJOK SMP SE-KECAMATAN TEGALLALANG-GIANYAR
}

\author{
I Made Doni' ${ }^{1}$, H. Wahjoedi², I Ketut Semarayasa ${ }^{3}$ \\ Prodi Pendidikan Jasmani Kesehatan dan Rekreasi \\ Jurusan Pendidikan Olahraga \\ Fakultas Olahraga dan Kesehatan \\ Universitas Pendidikan Ganesha \\ e-mail: madedoni97@gmail.com,Wahjoedi@undiksha.ac.id, \\ ketut.semarayasa@undiksha.ac.id
}

\begin{abstract}
ABSTRAK
Penelitian ini bertujuan ini untuk mengetahui seberapa lengkap sarana dan prasarana pendidikan jasmani olahraga dan kesehatan di Sekolah Menengah Pertama yang ada di seluruh kecamatan Tegallalang, kabupaten Gianyar, Bali. Penelitian ini tergolong dalam jenis penelitian deskriptif kuantitatif dimana penelitian ini merupakan sebuah metode penelitian yang memanfaatkan data kuantitatif dan dijabarkan secara deskriptif. Yang digunakan untuk medeskripsikan keadaan dari sebuah sekolah mengenai ketersediaan dalam hal sarana dan prasarana. Hasil penelitian ini didapatkan dengan cara survei langsung dengan pihak sekolah melalui khusunya guru PJOK yang ada disekolah SMP se-Kecamatan Tegallalang. Adapun hasil dari penelitian ini berdasarkan data yang didapat di lapangan adalah. Kategori baik dimiliki hanya 1 sekolah dengan presentase (25\%), untuk kategori sedang 2 sekolah dengan presentase (50\%), dan kategori kurang 1 sekolah (25\%) dan tidak ada sekolah yang masuk kedalam kategori sangat kurang. Maka dapat disimpulkan bahwa ada 1 sekolah yang memiliki sarana dan prasarana dengan kategori kurang yang ada di kec- Tegallalang. Dan adapun saran dari peneliti. Semoga sekolah yang memiliki kategori kurang dan sekolah memiliki kategori mampu menggunakan penelitian ini sebagai acuan untuk melengkapi ketersediaan sarana dan prasarana pendidikan jasmani olahraga yang belum dimiliki, agar lebih lengkap demi terciptanya proses pembelajaran yang efektif.
\end{abstract}

Kata-kata kunci : Survei, sarana dan prasarana pendidikan jasmani.

\section{ABSTRACT}

This study aims to determine how complete the facilities and infrastructure for sports and health physical education in junior high schools in all Tegallalang sub-districts, Gianyar regency, Bali. This research belongs to the type of quantitative descriptive research where this research is a research method that utilizes quantitative data and is described descriptively. Which is used to describe the state of a school regarding availability in terms of facilities and infrastructure. The results of this study were obtained by direct survey with the school through especially PJOK teachers in junior high schools in Tegallalang District. The results of this study are based on the data obtained in the field. The good category is owned by only 2 schools with a percentage (50\%), for the medium category 1 school with a percentage (25\%), and 1 school lacking category (25\%) and no school falls into the very poor category. So it can be concluded that there is 1 school that has poor facilities and infrastructure in Tegallalang sub-district. And there are suggestions from researchers. Hopefully, schools that have a poor category and schools that have a category are able to use this research as a reference to complement the availability of sports physical education facilities and infrastructure that are not yet owned, so that it is more complete in order to create an effective learning process.

Key words: Survey, physical education facilities and infrastructure. 


\section{PENDAHULUAN}

Pembelajaran merupakan proses penciptaan situasi dan kondisi yang memungkinkan peserta didik untuk proses belajar. Berbicara mengenai proses pembelajaran, tentu tidak akan terlepas dari ruang lingkup sekolah, yaitu mata pelajaran yang diajarkan di sekolah. Salah satu mata pelajaran yang ada di sekolah adalah pelajaran Pendidikan Jasmani, Olahraga dan Kesehatan (PJOK). PJOK merupakan mata pelajaran yang wajib diberikan secara formal.

Pendidikan jasmani merupakan bagian dari pendidikan (secara umum) yang berlangsung melalui aktifitas yang melibatkan mekanisme gerak tubuh manusia dan menghasilkan pola-pola prilaku individu yang bersangkutan. Pendidikan jasmani menurut Soepartono (2000 : 1) PJOK merupakan media untuk mendorong terjadinya sebuah perkembangan keterampilan motorik, kemampuan fisik, pengetahuan, penalaran penghayatan nilai (sikap, mental, emosional, spiritual, sosial), dan pembiasaan pola hidup sehat untuk merangsang pertumbuhan serta perkembangan yang seimbang. Sebagai guru dalam pembelajaran PJOK diharapkan mampu mengajarkan berbagai keterampilan gerak dasar, teknik dan strategi permainan dan olahraga, internalisasi nilai-nilai (sportivitas, jujur dan kerjasama) serta pembiasaan perilaku kehidupan yang ada di masyarakat.

Maka dalam pelaksanaan proses sebuah kegiatan proses belajar dan mengajar PJOK akan tidak dapat berjalan efektif tanpa adanya sebuah sarana dan prasrana olahraga yang lengkap untuk menunjang sebuah proses pembelajaran PJOK atau Olahraga baik itu di sekolah maupun luar sekolah. Peranan alat-alat penunjang untuk melakukan olahraga berupa sarana dan prasarana olahraga sangat diperlukan dalam proses kegiatan pembelajaran PJOK agar bisa terciptanya sebuah proses pembelajaran yang lebih efektif dan berjalan dengan optimal. Tanpa adanya kendala yang membuat waktu yang terbuang karena kendalas sarana dan prasarana yang kurang lengkap dan tidak sesuai dengan mata pelajaran akan akan diajarkan. Dengan demikian diharapkan sebuah proses pembelajaran PJOK disekolah-sekolah yang ada, mampu dan bisa berjalan.

Sesuai dengan harapan dan tujuan dari pembelajaran itu sendiri, maka dari itu penting untuk mengetahui seberapa kelengkapan dalam hal sarana dan prasarana yang dimiliki oleh sekolah agar sekolah mampu memberikan proses belajar dan mengajar di dalam pendidikan jasmani itu sendiri yang sesuai dengan keadaan sarana dan prasarana yang dimiliki oleh sekolah SMP yang ada di Kecamatan Tegallalang survei ini agar sekolah mengetahui seberapa lengkap sarana dan prasarana yang dimiliki sekolah agar sekolah mampu menyetarakan sarana dan prasarana yang dibutuhkan sesuai dengan mata pelajaran penjas. Sarana dan prasarana penjas merupakan factor penting dalam suksesnya pembelajaran penjas, sehingga peneliti ingin meneliti sarana dan prasarana penjas di SMP Negeri seKecamatan Tegallalang Kabupaten Gianyar.

Menurut abror hisyam (1991:2), faktor yang mempengaruhi perkembangan sarana dan prasarana yaitu : 1). Pertambahann jumlah penduduk, 2). Makin meluasnya daerah kota-kota, 3). Meningkatnya kesadaran masyarakat akan arti dan pentingnya olahraga, 4). Mobilitas transportasi meningkat, 5). Berkurangnya lapangan terbuka, meningkatnya mekanisme dalam industry, 7). Arus perpindahan penduduk dari desa ke kota, 8). Meningkatnya taraf hidup social ekonomi dan budaya. Dengan hal di 
atas maka sekolah diaharapkan mampu menyediakan sarana dan prasarana yang memadai untuk hasil pembelajaran penjas yang lebih baik agar dapat berjalan sesuai dengan kurikulum yang ada. Di SMP Negeri se-Kecamatan Tegallalang Kabupaten Gianyar masih terdapat beberapa SMP Negeri yang sarana dan prasana penjas yang masih kurang. Oleh karena itu, peneliti berusaha mencari kebenaran dari apa yang peneliti lihat di lapangan.

Berdasarkan hal tersebut, maka timbul suatu permasalah yang perlu diangkat dalam suatu penelitian yang berhubungan dengan sarana dan prasarana penjas di SMP Negeri seKecamatan Tegallalang Kabupaten Gianyar untuk hasil yang baik dan optimal bagi peserta didik dalam proses belajar dan mengajar dikelas.

\section{METODE PENELITIAN}

Penelitian tentang Survei Sarana dan Prasarana Pendidikan Jasmani Sekolah Menengah Pertama di Kecamatan Tegallalang ini menggunakan penelitian deskriftif kuantitatif. Prosesnya berupa pengumpulan dan penyusunan data-

\section{HASIL DAN PEMBAHASAN}

Rangkuman jumlah,kondisi dan status kepemilikan sarana dan prasarana data, analisis dan penafsiran data. Metode yang akan digunakan dalam penelitian ini adalah survei yang menggunakan angket dengan cara menghitung sarana dan prasarana penjas yang ada di SMP seKecamatan Tegallalang. Menggunakan metode survey supaya bisa melihat secara langsung di lapangan, bagaiaman keadaan sarana dan prasarana yang dimiliki SMP seKecamatan Tegallalang.

Definisi operasional dari penelitian ini merupakan jumlah keberadaan, kondisi dan status kepemilikan sarana dan prasarana penjas sebagai alat untuk tercapaianya tujuan pembelajaran penjas sehingga dapat terlaksana secara optimal sesuai dengan fungsinya. Keberadaan menjelaskan ada atau tidaknya serta berapa jumlah sarana dan prasarana yang dimiliki baik yang rusak dan baik sedangkan status dari kepemilikan agar bisa menjelaskan seberapa fasilitas sarana dan prasarana penjas yang milik sendiri dan meminjam. Dan untuk mengetahui itu semua maka akan digunakan lembar observasi untuk mencatat sarana dan prasarana penjas di SMP se-Kecamatan Tegallalang.

pendidikan jasmani olahraga dan kesehatan.

\section{Deskripsi Hasil Observasi Mengenai Jumlah Sarana Dan Prasarana Pendidikan Jasmani Olahraga Dan Kesehatan}

\begin{tabular}{|c|c|c|c|c|c|}
\hline \multirow{2}{*}{ Sekolah } & \multirow[t]{2}{*}{ Jumlah Keberadaan } & \multicolumn{2}{|c|}{ Kondisi } & \multicolumn{2}{|c|}{ Status kepemilikan } \\
\hline & & Baik & Buruk & Sendiri & Meminjam \\
\hline SMP N 1 Tegallalang & 74 & 72 & 2 & 70 & 4 \\
\hline SMP N 2 Tegallalang & 117 & 117 & & 113 & 4 \\
\hline SMP N 3 Tegallalang & 37 & 36 & 1 & 34 & 3 \\
\hline SMP N 4 Tegallalang & 91 & 91 & & 87 & 4 \\
\hline
\end{tabular}


Berdasarkan hasil analisis statistik dari tabel 9. Maka diperoleh hasil sebagai Mean $=79,75$ berikut: $\mathrm{SD}=33,54$

Deskripsi Hasil Observasi Mengenai Jumlah Sarana Dan Prasarana

\begin{tabular}{cccc}
\hline Rentangan Norma & Jumlah sekolah & Persentase & Kategori \\
\hline $96,52<x \leq 130,06$ & 1 & $25 \%$ & Baik \\
$62,98<x \leq 96,52$ & 2 & $50 \%$ & Sedang \\
$29,44<x \leq 62,98$ & 1 & $25 \%$ & Kurang \\
$x \leq 29,44$ & 0 & $0 \%$ & Kurang Sekali
\end{tabular}

Berdasarkan data di atas diketaui bahwa jumlah sarana dan prasarana pendidikan jasmani olahraga dan kesehatan disekolah dengan kategori baik 1 sekolah (25\%), kategori sedang 2 sekolah (50\%), kategori kurang 1 sekolah dan tidak ada sekolah yang masuk dalam kategori kurang sekali.

\section{Deskripsi Hasil Observasi Mengenai Kondisi Sarana Dan Prasarana Pendidikan Jasmani Olahraga Dan Kesehatan}

Berdasarkan hasil analisis statistik dari tabel 9. Maka diperoleh hasil sebagai berikut:

$$
\begin{aligned}
& \text { Mean }=79,00 \\
& S D=34,09
\end{aligned}
$$

Deskripsi Hasil Observasi Mengenai Kondisi Sarana Dan Prasarana

\begin{tabular}{cccc}
\hline Rentangan Norma & Jumlah sekolah & Persentase & Kategori \\
\hline $96,05<x \leq 130,14$ & 2 & $50 \%$ & Baik \\
$61,96<x \leq 96,05$ & 1 & $25 \%$ & Sedang \\
$27,87<x \leq 61,96$ & 1 & $25 \%$ & Kurang \\
$x \leq 27,87$ & 0 & $0 \%$ & Kurang Sekali \\
& & & \\
\hline
\end{tabular}

Berdasarkan data di atas diketaui bahwa kondisi sarana dan prasarana pendidikan jasmani olahraga dan kesehatan disekolah dengan kategori baik 2 sekolah (50\%), kategori sedang 1 sekolah (25\%), kategori kurang 1 sekolah dan tidak ada sekolah yang masuk dalam kategori kurang sekali.

\begin{abstract}
Deskripsi Hasil Observasi Mengenai Kepemilikan Sarana Dan Prasarana Pendidikan Jasmani Olahraga Dan Kesehatan

Berdasarkan hasil analisis statistik dari tabel 9. Maka diperoleh hasil sebagai berikut:
\end{abstract}

$$
\begin{aligned}
& \text { Mean }=76,00 \\
& S D=33,12
\end{aligned}
$$


Hasil Observasi Mengenai Kepemilikan Sarana dan Prasarana

\begin{tabular}{cccc}
\hline Rentangan Norma & Jumlah sekolah & Persentase & Kategori \\
\hline $92,56<x \leq 125,68$ & 1 & $25 \%$ & Baik \\
$59,44<x \leq 92,56$ & 2 & $50 \%$ & Sedang \\
$26,32<x \leq 59,44$ & 1 & $25 \%$ & Kurang \\
$x \leq 26,32$ & 0 & $0 \%$ & Kurang Sekali
\end{tabular}

Berdasarkan data di atas diketahui bahwa kepemilikan sarana dan prasarana pendidikan jasmani olahraga dan kesehatan disekolah dengan kategori baik 1 sekolah (25\%),

\section{KESIMPULAN}

Berdasarkan hasil analisis data dan pembahasan yang telah dilaksanakan maka dapat disumpulkan bahwa sarana dan prasarana pendidikan jasmani olahraga dan kesehatan di SMP se-Kecamatan Tegallalang Kabupaten Gianyar ialah sebagai berikut : Kategori jumlah keberadaan 1 sekolah (25\%), kategori sedang 2 sekolah (50\%), kategori kurang 1 sekolah (25\%) dan tidak ada sekolah yag masuk kedalam kategori sangat kurang.

Kategori kodisi baik 2 sekolah (50\%), kategori sedang 1 sekolah (25\%), kategori kurang 1 sekolah (25\%) dan tidak ada sekolah yag masuk kedalam kategori sangat kurang.

Kategori status kepemilikan 1 sekolah (25\%), kategori sedang 2 sekolah (50\%), kategori kurang 1 sekolah (25\%) dan tidak ada sekolah yag masuk kedalam kategori sangat kurang.

\section{DAFTAR PUSTAKA}

Agus S. Suryobroto.(2004). Diktat Mata Kuliah Sarana dan Prasarana Pendidikan Jasmani. Yogyakarta: FIK Universitas Negeri Yogyakarta.

Anas Sudijono. (2007). Pengantar Statistika Pendidikan. Jakarta: Grafindo Persada kategori sedang 2 sekolah (50\%), kategori kurang 1 sekolah dan tidak ada sekolah yang masuk dalam kategori kurang sekali.

Raju. Andri Tri Pratomo, (2013) Survei Sarana Dan Prasarana Pembelajaran Pendidikan

Jasmani Olahraga Dan Kesehatan Pada Sekolah Menengah Pertama Negeri Se-Kota

Purbalingga Tahun 2012. Under Graduates thesis, Universitas Negeri Semarang.

TELDI PATTIWAEL. (2018). Survei Sarana Dan Prasarana Pendidikan Jasmani Dan Olahraga Di SMP SeKecamatan Kota Selatan Kota Gorontalo.

E.Mulyasa. (2006). Kurikulum yang Disempurnakan. Yogyakarta: Rosada.

Harsuki (2003). Perkembangan olahraga terkini (kajian para pakar): Jakarta PT Rajagrafindo Persada.

Kadir, ljhar ( 2017). "Survei Sarana Dan Prasarana Pembelajaran Pendidikan Jasmani Olahraga dan Kesehatan di SMP Se-Kota Gorontalo Tahun 2017".

Nadisah. (1992). Perkembangan Kurikulum Pendidikan Jasmani dan Kesehatan. Bandung: Departemen Pendidikan dan Kebudayaan.

Soepartono. (2000). Sarana dan 
Prasarana Olahraga. Jakarta: Depdiknas.

Sugeng Purwanto. (2006). Pentingnya Pelaksanaan Pembelajaran Jasmani di
Administrasi

Pendidikan
Pendidikan Jasmani Indonesia. $(5,2006)$.

Sugiyono.(2006). Statistika Untuk Penelitian. Bandung: Alafabeta. UNY. (2003). Buku Pedoman Penyusunan Tugas Akhir. Yogyakarta. 